\title{
Pharmaceutical ethnobotany in the Mahabad (West Azerbaijan) biosphere reserve: ethno-pharmaceutical formulations, nutraceutical uses and quantitative aspects
}

\author{
Saeed Jafarirad ${ }^{1,2, *}$, Ibrahim Rasoulpour ${ }^{1}$ \\ ${ }^{1}$ Research Institute for Fundamental Sciences (RIFS), University of Tabriz, Tabriz, Iran, ${ }^{2}$ Faculty of Traditional Medicine, \\ Tabriz University of Medical Sciences, Tabriz, Iran
}

\begin{abstract}
This study endeavors to overcome the limits of an orally transmitted pharmacopoeia, and tries to utilize the large ethnobotany patrimony of the area to investigate the biological diversity. Thirty-five traditional practitioners from dissimilar ethnic groups including traditional health practitioners (THPs) and indigenous people were interviewed. A total of 35 species of plants, belonging to 20 families were recognized for the treatment of more than 26 types of ailments. Informant consensus factor (FIC) values of this study reflected the high agreement in the use of plants in the treatment of gastro-intestinal complaints, infectious, parasitic diseases and constipation among the informants. Constipation had the highest use-reports and 8 species of plants had the highest fidelity level (FL) of $100 \%$. In addition one of the species showed the highest relative importance (RI) value of 2.00. Priority should be given to phytochemical investigation of plants that scored the highest FL, FIC, RI values; as such values could be considered as a good indicator of potential plants for discovering new drugs. In addition, traditional knowledge of THPs should be taken into consideration in order to smooth continuation and extension of the nutraceutical aspects and biological diversity of the region.
\end{abstract}

Keywords: Pharmaceutical Ethnobotany. Ethno-Medicinal Knowledge. Indigenous people. Nutraceutical aspects. Ethnobotany/trends. Biosphere/analysis. Medicine tradicional/utilization. Ethnopharmacology. Plants/drug effects. Phytochemicals/pharmacology.

\section{INTRODUCTION}

Ethno-Medicinal studies of plants with therapeutic properties are very beneficial for the discovery of modern remedies (Cox, Balick, 1994; Bitu et al., 2015; Baydoun et al., 2015; Heinrich, Gibbons, 2001; Kpodar et al., 2015; Samoisy, Mahomoodally, 2015; Tchouya et al., 2015). According to the World Health Organization (WHO), about 4 billion people in developing countries not only trust in the therapeutic properties of medicinal plant but also use them consistently (Rai, Prasad, Sharma, 2000; Chintamunnee, Fawzi Mahomoodally, 2012; Yavuz et al., 2015). Among developing countries, Iran is a vast country of rich plant resources including considerable number of medicinal plants (Mosaddegh et al., 2012; Jafarirad, Damanafshan, 2017) (Figure 1). Increasing attention to medicinal plants use in Iran could be attributed

\footnotetext{
*Correspondence: S. Jafarirad. Research Institute for Fundamental Sciences (RIFS), University of Tabriz, 29 Bahman Bld. Tabriz, Iran. E-mail: jafarirad@tabrizu.ac.ir
}

to both the increasing price of modern remedy drugs and prevalence of side effects of chemical drugs (Mosaddegh et al., 2012). In the villages of Mahabad, there are only a few pharmacies or they are totally absent; the villagers cannot easily reach cities to receive chemical remedies. For this reason, in every village there is a bazaar in which all commercial activities are situated. Among the various shops there are those where traditional remedies, seeds, fruits, drugs and spices are sold.

Mahabad, in West Azerbaijan and parts of Kurdistan, has a variety of vegetation zones due to climate and good rainfall years. The first name of Mahabad was Savoujbolagh. Savoujbolagh is a Turkish word meaning cold spring. Later, the town was called Savoujbolagh Mokri, meaning Savoujbolagh of the Mukri tribe, due to the residence of the Mukri tribe in the town (McDowall, 1996).

Documentation of the traditional knowledge through ethnopharmacological evaluations is vital for conservation of bio-resources (Heinrich, Gibbons, 2001). The diverse manners of people life in district of Mahabad have resulted 
in a various local health care system. Unfortunately, in the recent years, medicinal plants and the related data are being extremely exhausted in Mahabad. It could be as a result of deforestation, environmental degradation and migrations of traditional medicinal healers to other jobs. It has been taking place in the country for rather an extensive time, which could ultimately result in the quick loss of the traditional knowledge. Moreover, the information on traditional preparation of medicinal plants has been passed from one generation to the next only orally. Thus most of the written documents of this field are not available. In general, in the past decades a few of pharmacological surveys have been carried out as the customary uses of plants in Iran (Miraldi, Ferri, Mostaghimi, 2001; Ghorbani, 2005; Mosaddegh et al., 2012). In particular, in spite of the existence of a rich culture of use of traditional herbs in Mahabad, there are not any ethnobotanical investigations so far. Therefore, an ethnobotanical survey of medicinal plants utilized by the indigenous people in Mahabad was conducted in order to document the information regarding traditional uses of medicinal plants and identify the most important species used in traditional medicine. Moreover, a comparative investigation on acquired data and goals of application of these traditionally used plants was attempted.

\section{MATERIALS AND METHODS}

\section{Study area}

Mahabad city and its villages (Figure 1), with an area of $2591 \mathrm{~km}^{2}$, are approximately located in the north west of Iran at $36^{\circ} 45^{\prime} 47^{\prime \prime} \mathrm{N}$ and $45^{\circ} 43^{\prime} 20^{\prime \prime} \mathrm{E}$. The city lying south of Urmia Lake in a narrow valley 1,300 meters above sea level with annual average temperature of $12{ }^{\circ} \mathrm{C}$ as well as annual rainfall is $330 \mathrm{~mm}$. The area has a continental climate with rather hot summers and cold winters. The area is characterized by two main ecosystems; forest and steppe. In the wild areas we mostly observe vegetation and the land is covered in lush, but due to human activities and lack of rainfall it is significantly declined in recent years. At the 2006 census, the city's population was 197,441 (Bakhtiyari, 2015). The main language of the indigenous population is Kurdish (Laizer, 1996).

\section{Selection of informants}

Interviewees were local traditional health practitioners (THPs) in addition to native people with practical or experiential information on medicinal plants. A total of 35 people were interviewed for this study. The

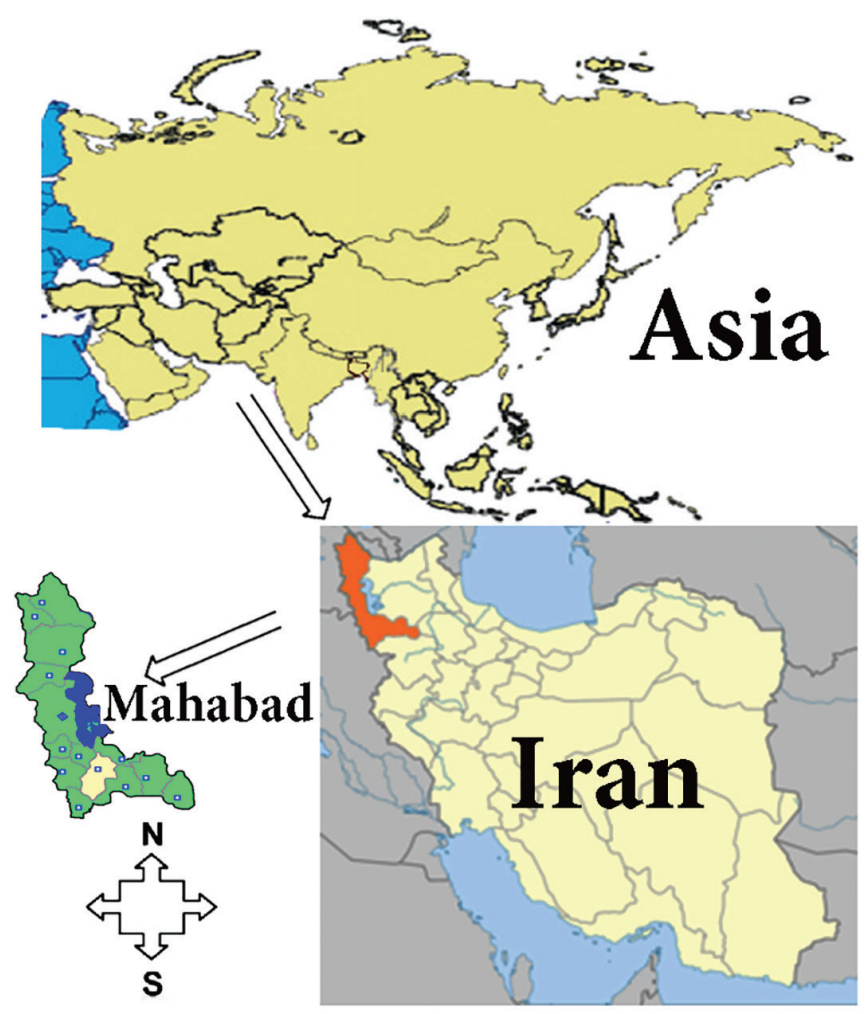

FIGURE 1 - Location of study area, Mahabad, in Iran Map

informants were selected as they were known as being traditional health practitioners by the local Mahabad community. Besides THPs, elderly individuals of the region, experienced people, shepherds and medicinal plant vendors were also interviewed. During the selection of informants, gender, age, educational background, and experience on use of traditional medicinal plants were taken into consideration (Table I). The interviews were conducted by the second author at the THPs house and Bazar (markets in local language) in Mahabad. Local Kurdish language was used in the interview. Informants were asked to report the wild, cultivated or bought medicinal plants that had been traditionally used in the area, what ailments were treated with them, and whether they were still in use or abandoned. We also asked the local names of the plants, and how they were collected, conserved, prepared, and administered. During the interview, informants also mentioned medicinal plant uses that they had learned via non-traditional sources such as internet courses and books. This information was registered as modern medicinal uses and was not included as medicinal plants traditionally used in the region.

\section{Ethnomedicinal data collection}

The aims of the study were obviously clarified and consents were obtained by interviewers from each 
TABLE I - Demographic data of the informants

\begin{tabular}{lccc}
\hline Variable & Categories & No. of person & Percent \\
\hline Informants & Traditional health practitioners & 3 & 8.57 \\
category & Indigenous people & 32 & 91.43 \\
\hline \multirow{2}{*}{ Gender } & Male & 25 & 71.42 \\
& Female & 10 & 28.59 \\
\hline & Less than 20 years & - & - \\
& $20-30$ years & 1 & 2.85 \\
Age & $30-40$ years & 4 & 11.42 \\
& $40-50$ years & 14 & 40 \\
& $50-60$ years & 10 & 28.5 \\
& More than 60 years & 6 & 17.14 \\
\hline \multirow{2}{*}{ Educational } & Illiterate & 16 & 45.7 \\
background & Completed five years education & 11 & 31.42 \\
& Completed eight years education & 4 & 11.42 \\
& Completed 12 years education & 1 & 2.86 \\
Experience of the & Somer & 1 & 2.86 \\
traditional health & under grade degree (16 years education) & 2 & 5.71 \\
practitioners & Graduate (higher education) & 5 & 14.28 \\
\hline
\end{tabular}

informant. Each informant was questioned alone to ensure confidentiality among them.

Open-ended and semi-structured questionnaire (Cotton, 1996) was used for the purpose. The questionnaire was presented in two parts. Part 1 covered personal information including age, sex, educational background, and experiences of the informants related to medicinal plants (Table I). Part 2 was about their practice including the following information (Table II); (i) local name of the plants, (ii) used part(s) of plants, (iii) mode of preparation, (iv) medicinal uses of particular plants, (v) harvest time and (vi) relative abundance of species at the area, they are found up to $80-90 \%, 40-50 \%$ and less than $10 \%$ in which stand for abundant, medium and rare, respectively. In addition, it must be mentioned that the local people had not any information about the toxicity effects of the species that they have used.

The collected voucher specimens were pressed, preserved and later identified by the Herbarium of research institute of natural resources of West Azerbaijan, Urmia. Most plant species were collected together with the informants and in some cases; plants were collected in a later visit in the same location where the informant lived. Research articles, books and relevant web pages were studied with the purpose to collect data of phytochemicals present in the plants. Then frequently found compounds in the reported plant species were listed.

\section{Data analysis}

The plants were recorded in alphabetical instruction by scientific name, family, local name, general name, used part(s) of plants, mode of preparation, mode of application, relative abundance, conservation status and frequency of citation (FC) (Table IV). The FC of the plants species being utilized was evaluated using the formula:

$\mathrm{FC}=($ Number of times a particular species was mentioned/ total number of times that all species were mentioned) $\times 100$

The informant consensus factor (FIC) was considered with the following (Heinrich, Gibbons, 2001).

$$
\mathrm{FIC}=(\mathrm{Nur}-\mathrm{Nt}) /(\mathrm{Nur}-1)
$$

where 'Nur' refers to the number of use-reports for a particular ailment category and ' $\mathrm{Nt}$ ' refers to the number of taxa used for a particular ailment category by all informants. FIC was applied to focus the sameness of the information about a specific plant use to treat a specific kind of illnesses (Table V). In other words, the FIC is a symbolic value of stability of the informants that how regularly they agree about the use of certain plant species for the dealing of a particular ailments category. The product of this factor ranges from 0 to 1 . An illness having a high FIC value (close to 1 ) shows that relatively few taxa are used by a large proportion of the informants. A low 
TABLE II - Ethnomedicinal data collection

\begin{tabular}{|c|c|c|c|c|c|c|c|c|}
\hline Local name & Persian name & Scientific Name & Used part & How to use & Usage & Harvest time & Abundance & $\begin{array}{l}\text { No. of } \\
\text { person }\end{array}$ \\
\hline Gala rakesha & Barhang & $\begin{array}{c}\text { Plantago major } \\
\text { L. }\end{array}$ & Leaf & unprepared & $\begin{array}{l}\text { Analgesic for toothache, } \\
\text { extirpation of body acne and } \\
\text { suppurative }\end{array}$ & Spring & Abundant & 9 \\
\hline Talkhe talkhe & Talkhe Talkhe & Acropilon repens & Stem & unprepared & Diabetes & Spring & Abundant & 4 \\
\hline Gharbang & Panj Angosht & $\begin{array}{l}\text { Vitex agnus } \\
\text { castus }\end{array}$ & Seed & Burning & Elimination of Dental larva & Spring & Abundant & 12 \\
\hline Bezhan & Boomadaran & $\begin{array}{c}\text { Achillea } \\
\text { millefolium }\end{array}$ & Leaf & Decoction & Washing & Spring & Abundant & 1 \\
\hline Gogam & Gole mahoor & $\begin{array}{l}\text { Verbascum } \\
\text { thapsus }\end{array}$ & Leaf & Unprepared & Skin burning & Spring & Abundant & 1 \\
\hline Shilan & Nastaran & Rosa Canina & Fruit Leaf & Infusion & Elimination of Diabetes & Autumn & Abundant & 3 \\
\hline Revas & Rivas & Rheum ribes & Root & Infusion & Elimination of Diabetes & Spring & Abundant & 6 \\
\hline Memook & Shirin bayan & $\begin{array}{l}\text { Glycyrrhiza } \\
\text { echinata }\end{array}$ & Bulb & Infusion & stomach ache & Spring & Abundant & 30 \\
\hline Hero & Khatmi & $\begin{array}{l}\text { Althaea } \\
\text { officinalis }\end{array}$ & Flower & Decoction & $\begin{array}{l}\text { Strong laxative, Extirpation } \\
\text { of body acne, Expectorant }\end{array}$ & Spring & Abundant & 3 \\
\hline Hamisha bahar & Hamishe bahar & $\begin{array}{l}\text { Calendula } \\
\text { Officinalis }\end{array}$ & Sap & Unprepared & Laxative & Spring & Abundant & 15 \\
\hline Gog nasa & Piaz e Anasal & Drimia maritima & Bulb & Powder & $\begin{array}{c}\text { Extirpation of body acne, } \\
\text { softener }\end{array}$ & Spring & Abundant & 5 \\
\hline Pr Pra & Kharfe & $\begin{array}{c}\text { Portulaca } \\
\text { oleraceae L. }\end{array}$ & Leaf & Infusion & Elimination of Diabetes & Spring & Abundant & 5 \\
\hline Kartashi & Shekar tighali & $\begin{array}{c}\text { Echinops ritrodes } \\
\text { Bunge }\end{array}$ & Sap & Infusion & Laxative & Spring & Abundant & 13 \\
\hline Pnga & Pooneh & $\begin{array}{c}\text { Mentha } \\
\text { longiflorum }\end{array}$ & Leaf, Stem & Infusion & Laxative, Carminative & Spring & Abundant & 15 \\
\hline Yonje & Yonje & Medicago Sativa & Leaf & Infusion & Hematological diseases, & Spring, summer & Abundant & 7 \\
\hline Haji laklak & Panirak & Malvasyl vestris & Leaf & Decoction & Laxative, cough & Spring & Abundant & 1 \\
\hline Galay havidar & Baba Adam & Artium lappa & Leaf, Root & $\begin{array}{l}\text { Infusion, } \\
\text { Decoction }\end{array}$ & $\begin{array}{l}\text { Cardiovascular diseases, } \\
\text { Dermatology problem, } \\
\text { Stomach worms, Sore } \\
\text { throat, }\end{array}$ & $\begin{array}{l}\text { Summer, } \\
\text { Autumn }\end{array}$ & Rare & 1 \\
\hline Chagh chagha & Ka'asnii & $\begin{array}{l}\text { Chicoriom } \\
\text { Intybus }\end{array}$ & Leaf & Decoction & Cardiovascular diseases & Spring & Abundant & 1 \\
\hline Dara bii & Biid & Salix alba & Leaf, Fruit & Infusion & Sedative an Sleeping & Spring & Abundant & 3 \\
\hline Bayboon & Babooneh & $\begin{array}{l}\text { Anthemis } \\
\text { tinctoria }\end{array}$ & Leaf, Fruit & Infusion & stomach ache, vomiting & Spring & Abundant & 4 \\
\hline Voshtr khorka & Khar shotor & $\begin{array}{c}\text { Alhagi } \\
\text { camelorum }\end{array}$ & $\begin{array}{l}\text { Bark, Stem } \\
\text { Fruit }\end{array}$ & Infusion & Kidney Stones & Spring & Abundant & 3 \\
\hline
\end{tabular}


TABLE II - Ethnomedicinal data collection (cont.)

\begin{tabular}{|c|c|c|c|c|c|c|c|c|}
\hline Local name & Persian name & Scientific Name & Used part & How to use & Usage & Harvest time & Abundance & $\begin{array}{l}\text { No. of } \\
\text { person }\end{array}$ \\
\hline Pakoola & Khar khasak & $\begin{array}{l}\text { Tribulus } \\
\text { terrestris }\end{array}$ & Leaf, Fruit & Infusion & Kidney Stones & Spring & Medium & 2 \\
\hline Friizoo & Biid giyah & Cyndon dactylon & Leaf, Fruit & Infusion & $\begin{array}{l}\text { Kidney Stones, epilepsy and } \\
\text { antidepressive }\end{array}$ & Spring & Medium & 2 \\
\hline Gppzrovan & Gav zaban & $\begin{array}{l}\text { Borago } \\
\text { officinalis }\end{array}$ & Leaf, Fruit & Infusion & Kidney Stones & Spring & Medium & 2 \\
\hline Mazoo & Mazoo & $\begin{array}{l}\text { Quercus } \\
\text { infectoria }\end{array}$ & Fruit & Infusion & eyesight & Autumn & Abundant & 3 \\
\hline Darbnav & Zaban gonjeshk & $\begin{array}{l}\text { Fraxinus } \\
\text { excelsior } L \text {. }\end{array}$ & Bark & Unprepared & $\begin{array}{c}\text { Cyst weakness, vermifuge } \\
\text { and sterility }\end{array}$ & $\begin{array}{l}\text { Summer, } \\
\text { Autumn }\end{array}$ & Rare & 3 \\
\hline Giasalma & Sa'alab & Orchis palustris & Bulb & Infusion & Ice cream, Weak laxative & Spring & Rare & \\
\hline Chnar & Chenar & $\begin{array}{l}\text { Platanus } \\
\text { orientalis }\end{array}$ & Stem & Infusion & Tonic & - & Abundant & 1 \\
\hline
\end{tabular}

value indicates that informants disagree on the taxa to be used to heal a specific category of illness.

Relative Importance Value (RI) was determined according to the work of Bennett, Prance (2000) as:

$$
\mathrm{RI}=\mathrm{PP}+\mathrm{AC}
$$

where PP is obtained by the number of pharmacological properties, reported specific ailments, attributed to a species divided by the maximum number of properties attributed to the most resourceful species (species with the highest number of properties). The AC stands for number of Ailment Categories treated by a given species divided by the maximum number of ailment categories treated by the most resourceful species. The highest possible value of $\mathrm{RI}$ is 2.0 , which indicates the highest diversity of medicinal uses of a plant (Table VI).

Fidelity Level (FL) was intended using the following formula (Friedman et al., 1986) as:

$$
\mathrm{FL}=\mathrm{Ip} / \mathrm{Iu} \times 100
$$

where Ip is the number of informants who independently indicated the use of a species for the same major ailment and $\mathrm{Iu}$ is the total number of informants who mentioned the plant for any major ailment. High FL value shows high frequency of use of the plant species for dealing a particular ailment category by the informants of the study area (Table VII).

\section{RESULTS}

\section{Informants}

Among the 35 interviewees, 3 people are THPs and the others are indigenous people. Percentage of men and women in this study were 28 and 72, respectively. There was a high percentage, nearly $50 \%$, of interviewees who were around 40-50 years old. In addition, the majority of interviewees were illiterate (Table I).

\section{Medicinal plants reported}

In the present study, 35 plant species belonging to 20 plant families are identified as having medicinal values by THPs in mahabad. Asteraceae with 7 species (belonging to Acroptilon repens, Achillea millefolium, Calendula Officinalis, Echinops adenocaulos, Arctium Lappa, Chicoriom Intubus and Matricaria chamomilla), Rosaceae with 3 species (belonging to Rosa Canina, Crataegus aronia and Rubus fruticosus), Fabaceae with 3 species (belonging to Glycyrrhiza glabra, Castanea sativa and Quercus infectoria) and the other family are according the Table 3 and Figure 2.

\section{Information regarding the preparation}

Depending on plant and illness sometimes whole plant and in many cases different parts of the same plant including leaf, root, bark, fruit, flower, rhizome, seed, 


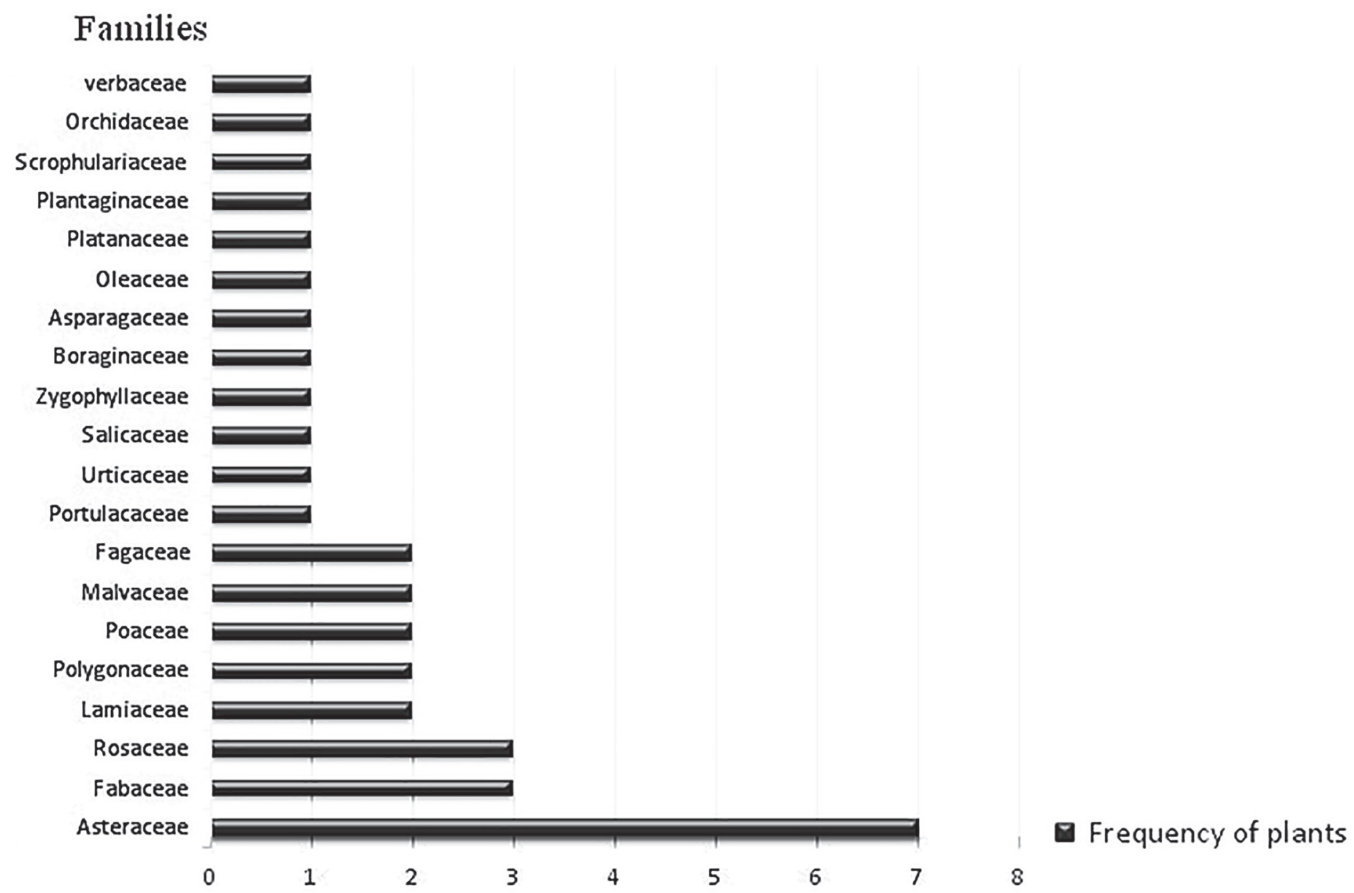

FIGURE 2 - Families of the plants with their frequencies

stem, tuber and bulb are used for the management of various ailments. Most of time, different parts are blended together for a medicinal preparation. Approximately, for all plants, the leaves were used. Different preparation methods are used for ordering herbal medicinal plants including decoction, infusion, juice, powder, maceration and raw. The main mode of preparation is infusion followed by decoction. Moreover, the most cited plants are Glycyrrhiza glabra L., Thymus kotschyanus Boiss. and Echinops ritrodes Bunge.

\section{Other relevant information of the recorded medicinal plants}

As shown in Table IV, the majority of reported plants have been used for more than one type of illness. The highest proportions of medicinal plants are used to treat constipation ( 7 species), infectious and parasitic diseases (6 species), cardiovascular diseases ( 5 species), gastrointestinal complaints (4 species) and diabetes (5 species).

Table V summarizes the FIC values obtained for the categorized ailment. The FIC values in our investigation ranged from 0 to 1 . The ailments categories with more than 8 use-reports are constipation (79 use-reports, 7 species), gastrointestinal complaints (60 use-reports, 4 species), infectious and parasitic diseases (31 use-reports), 6 species and cardiovascular (17 use-reports, 5 species). In our study, the highest FIC value (0.95) was found for gastrointestinal complaints, followed by constipation
(0.92) and infectious and parasitic diseases (0.83).

Arctium lappa L. possessed the maximum number of pharmacological properties (5 properties) so it had a regularized PP value of 1.00 (5/5). Arctium lappa L. has been employed to treat 5 ailments categories and had a regularized AC value of $1.00(5 / 5)$ which possessed the highest RI value of 2.00 followed by RI 1.2 of Achillea millefolium L. (Table VI). Moreover, 19 plants mentioned by 5 or more informants for being used against a given ailment category. Among these plants 4 species were cited for constipation and dermatology problem separately. Furthermore, 9 plants showed the maximum amount of FL including Thymus kotschyanus Boiss., Mentha longiflia L., Arctium lappa L., Glycyrrhiza glabra, Arctium lappa, Drimia maritimia, Platanus orientalis, Medicago sativa and Rheum ribes.

\section{A detailed evaluation on FL, FIC, RI values}

In the present investigation, about $45 \%$ of THPs were illiterate, but they had rather good knowledge on traditional remedies (Table I). For example, they used more than one part of the plant for the preparation of remedies based on the rules of Iranian traditional medicine which is consisted of four humours concept: Phlegm (Balgham), Blood (Dam), Yellow bile (Safra) and Black bile (Sauda) (Afshar, 1992; Zargari, 1992; Mir Heidari, 1993). These THPs firmly conserve certain rules in regards to collecting plants at some particular months of the year, and in 
TABLE III - Genus and species of the plants

\begin{tabular}{|c|c|c|c|}
\hline Species & Genus & Family & Local name \\
\hline Plantago major L. & Plantago & Plantaginaceae & Gala rakesha \\
\hline Acroptilon repens & Acroptilon & Asteraceae & Talkhe talkhe \\
\hline Vitex agnus castus & Vitex & Verbaceae & Gharbang \\
\hline Achillea millefolium & Achillea & Asteraceae & Bezhan \\
\hline Verbascum thapsus & Verbascum & Scrophulariaceae & Gogam \\
\hline Thymus kotschyanus & Thymus & Lamiaceae & Jatra \\
\hline Rosa canina & Rosa & Rosaceae & Shilan \\
\hline Rheum ribes & Rheum & Polygonaceae & Revas \\
\hline Glycyrrhiza glabra & Glycyrrhiza & Fabaceae & Memook \\
\hline Althaea officinalis & Althaea & Malvaceae & Hero \\
\hline Calendula officinalis & Calnedula & Asteraceae & Hamisha bahar \\
\hline Drimia maritima & Drimia & Asparagaceae & Gog nasa \\
\hline Portulaca oleraceae L. & portulaca & Portulacaceae & Pr Pra \\
\hline Rumex acetosella & Rumex & Polygonaceae & Trsha ga \\
\hline Phragmites australis & Phragmites & Poaceae & Goli ghamish \\
\hline Urtica dioica & Urtica & Urticaceae & Gaz gask \\
\hline Echinops adenocaulos & Echinops & Asteraceae & Kartashi \\
\hline Mentha pulegium & Mentha & Lamiaceae & Pnga \\
\hline Medicago sativa & Medicago & Fabaceae & Yonje \\
\hline Malva sylvestris & Malva & Malvaceae & Haji laklak \\
\hline Arctium lappa & Aectium & Asteraceae & Galay havidar \\
\hline Chicoriom intubus & cichorium & Asteraceae & Chagh chagha \\
\hline Salix alba & salix & Salicaceae & Dara bii \\
\hline Matricaria chamomilla & Matricaria & Asteraceae & Bayboon \\
\hline Alhagi mamurorum & Alhagi & Fabaceae & Voshtr khorka \\
\hline Tribulus terrestris & Tribulus & Zygophyllaceae & Pakoola \\
\hline Cyndodom mactylon & Cynodon & Poaceae & Friizoo \\
\hline Borago officinalis & borago & Boraginaceae & Gppzrovan \\
\hline Castanea sativa & Castanea & Fabaceae & Baroo \\
\hline Quercus infectoria & Quercus & Fabaceae & Mazoo \\
\hline Fraxinus excelsior & Fraximus & Oleaceae & Darbnav \\
\hline Crataegus aronia & Crataegus & Rosaceae & Zalzalak \\
\hline Rubus fruticosus & Rubus & Rosaceae & Drdook \\
\hline Platanus orientalis & Platanus & Platanaceae & Chnar \\
\hline Orchis masculata & Orchis & Orchidaceae & Giasalma \\
\hline
\end{tabular}

compounding those various plants along with their time usage. In general, the local people of Mahabad were more familiar than urban people in respect of recognition of local medical knowledge of plants. It may be due to the fact that the local people have much more experience concerning plants from their childhood. Most plants reported in this study were related to the family Asteraceae as the largest family with 23,000 species. The wide-spread popularity of this family was similar to published ethnophamacological report from Golestan province, Iran (Ghorbani, 2005). It appears that the great success of Asteraceae as the largest family was due to the development of the highly 
TABLE IV - Aliments grouped by different ailment categories (several diseases based on the similarity in one category)

\begin{tabular}{llc}
\hline Illness categories & Medical terms & $\begin{array}{c}\text { No of species } \\
\text { used }\end{array}$ \\
\hline Gastro-intestinal complaints & Stomachic, leprous ulcer, obstinate ulcer, anthelmintic, diarrhea, & 4 \\
& Dysentery & \\
Respiratory problems & Cough, chronic bronchitis, asthma, hemoptysis, expectorant & 3 \\
Diabetes & Diuretic, antihyperglycemic & 4 \\
Cardiovascular diseases & Hypertension & 5 \\
Infectious and parasitic diseases & Antiseptic & 6 \\
Ear, nose, throat disorder (ENT) & Gout, catarrhal & 1 \\
Venomous bites & scorpion-sting, snake-bite & 1 \\
Tonics & Stimulant, alterative & 2 \\
Female problems & Emmenagogue, menorrhagia & 1 \\
Constipation & Laxative, cathartic, Purgative & 7 \\
Dermatology problem & Demulcent, emollient, eruptions, Singe & 3 \\
Kidney problems & All kides of disorders & 5 \\
\hline
\end{tabular}

TABLE V - Informant consensus factor (FIC) for categorized ailments

\begin{tabular}{lccc}
\hline Ailment category & Number of use reports (Nur) & Number of taxa (Nt) & $\begin{array}{c}\text { Informant consensus factor } \\
\text { (FIC) }\end{array}$ \\
\hline Gastro-intestinal Complaints & 60 & 4 & 0.95 \\
Respiratory problems & 10 & 3 & 0.77 \\
Diabetes & 18 & 4 & 0.82 \\
Cardiovascular diseases & 17 & 5 & 0.75 \\
Infectious and parasitic diseases & 31 & 6 & 0.83 \\
Ear, nose, throat disorder (ENT) & 1 & 1 & 0.00 \\
Venomous bites & 1 & 1 & 0.00 \\
Tonics & 4 & 2 & 0.66 \\
Female problems & 1 & 1 & 0.00 \\
Constipation & 79 & 7 & 0.92 \\
Dermatology problem & 10 & 3 & 0.77 \\
Kidney stone & 13 & 5 & 0.66 \\
\hline
\end{tabular}

specialized capitulum as well as its ability to store energy as fructans (Stevens, 2001). Most parts of the plants used by the indigenous people were leaves followed by roots and stems (Table III). It may be as a result of the fact that the leaves are leading organs of photosynthesis and accordingly have photosynthetic chemicals which might be responsible for medicinal values (Balick, Cox, 1996; Ghorbani, 2005). Moreover, the leaves could be picked easier than the other part of plants such as root and stem. In addition, there are much more methods for preparing them as herbal remedies (Poffenberger et al., 1992; Giday,
Asfaw, Woldu, 2010; Rehecho et al., 2011; Telefo et al., 2011). Based on our results, the frequently used mode of preparation is decoctions, infusions and powder, which are practiced by the patients themselves. Powder form of remedies is often administered with honey. Most plants used in this study were as annuals and perennial plants.

From the interviews it could be considered that traditional medicine exploits only Glycyrrhiza echinata, wild species which grow in the Mahabad, whereas the formal Iranian traditional medicine reports only Glycyrrhiza glabra (Table II). Moreover, Thymus 
TABLE VI - Relative Importance (RI) values for Mahabad medicinal plants used against or more specific use categories and three or more ailments categories treated

\begin{tabular}{lccc}
\hline Species & PP & AC & RI \\
\hline Artium lappa & 1 & 1 & 2.00 \\
Achillea millefolium & 0.6 & 0.6 & 1.2 \\
Fraxinus excelsior L. & 0.6 & 0.4 & 1.00 \\
Thymus kotschyanus & 0.4 & 0.2 & 0.6 \\
Medicago sativa & 0.4 & 0.2 & 0.6 \\
Anthemis tinctoria & 0.4 & 0.4 & 0.8 \\
\hline
\end{tabular}

kotschyanus Boiss.is employed by local people to provide refreshing baths, but they never know its toxicity. It is due to the fact that its protracted use can cause hyperemia and serious inflammations. Furthermore, this toxicity is known for Thymus kotschyanus Boiss. in Iranian sources (Afshar, 1992; Zargari, 1992; Mir Heidari, 1993), and for other species of the genus Thymus in other scientific reports (Duke, 1988; Longo, 1994). Hence, it appears that a good knowledge of folk healers of medicinal plants is necessary to educate local people on the toxicity of plants. Therefore, it appears that in some cases, medicinal plants must be assessed scientifically. This may be performed via confirmation of the pharmacological effects of the used species and correlating their effects with their phytochemicals. Thus, such recognition could supply further progress to modify the efficacy and safety of the local remedies.

Several plants like Achillea millefolium L. are known for their value in veterinary medicine, for example against haematuria and scabies. Most of the reported species are present in formal Iranian traditional medicine, but not in every occasion the actions attributed to a plant were the same. For instance, the formal traditional sources do not report the use of Plantago major as an analgesic for toothache, the use of Cynodon dactylon (L.) Pers. as an antidepressant and antiepileptic, and finally the use of Fraxinus excelsior L.as a vermifuge (Table II).

In several cases, the consumed part of the species exploited in traditional remedies is different from that employed in Iranian formal sources. For example, the informants used all parts of Cynodon dactylon (L.) Pers. to provide infusions, whereas only the roots and rhizomes were reported by Iranian formal sources (Rojhan, 1991; Amin, 1991; Afshar, 1992; Zargari, 1992; Mir Heidari, 1993).

Judging by the information obtained, a great number of indigenous plants are used to treat both gastrointestinal diseases and skin problems including burns, bites and purulent rash (Table IV). This was mainly because there are no proper medical facilities especially in rural areas where indigenous people are physically involved with various kinds of both gastrointestinal and skin problems. It is interesting that THPs use remedies consisting of several plants mixed together in order to have a more effective action, while in local medicine of Mahabad it is more common to use only one plant for each remedy, but there are a few mixtures widely known and used such as the "four seeds" which is famous in the area.

Respiratory diseases with maximum FIC show the most consent of the indigenous people in using the species of Urtica dioica L.to treat these problems (Kadir et al., 2012) (Table V). A high FIC also depicts the possibility of containing key phytochemical ingredient(s) in these plants (Neves et al., 2009). The reasons for the low value of the FIC can be due to (i) development of human society which followed by local people (Al-Qura'n, 2009); (ii) lack of exact classification of these illnesses in the rural regions (Ragupathy et al., 2008); (iii) lack of proper connect between local people owing to lack appropriate facilities (Rokaya, Münzbergová, Timsina, 2010) and (iv) large number of medicinal plants to treat a particular kind of illness that causes lack of inconsistency (Ragupathy et al., 2008; Al-Qura'n, 2009; Rokaya, Münzbergová, Timsina, 2010).

Arctium lappa L. scored the maximum amount of RI (Table VI). It may be attributed to two parameters as (i) more versatility against more illnesss (Ayyanar, Ignacimuthu, 2011) and (ii) more abundance in the area (Giday, Asfaw, Woldu, 2010).

The FL values of medicinal species are cited by THPs for being used against a given ailment category. It means that whatever the amount of FL is greater, then THPs have used these plants further. Hence, the species with the highest FL values are more likely to be bio-active; accordingly, they possess good healing potential for a specific ailment. In other words, it implies the prevalence of particular ailments, in Mahabad, that are treated with the medicinal plants with high FL values. Table VII shows the maximum value of the FL for 9 species.

The obtaining of the highest core of Glycyrrhiza glabra L., Thymus kotschyanus Boiss. and Mentha longiflia L.in the results of our survey could be assigned to four reasons; (i) their excellent, rapid and versatile healing properties (ii) their high abundance around the area and finally (iii) and their ease of preparation as medicine.

According to our results, the experiences of THPs have not been acquired via scientific sources and this experience is transmitted from generation to generation as orally. However, currently, the uses of medicinal 
TABLE VII - Fidelity Level (FL) values of medicinal plants

\begin{tabular}{|c|c|c|c|c|c|}
\hline Medicinal plants & Aliment category & Specific ailment & $\mathrm{Ip}^{\mathrm{a}}$ & $\mathbf{I u}^{\mathrm{b}}$ & FL value (\%) \\
\hline Thymus kotschyanus & Constipation & Laxative & 25 & 25 & 100.00 \\
\hline Calendula officinalis & Constipation & Laxative & 15 & 18 & 83.00 \\
\hline Echinops ritrodes Bunge & Constipation & Laxative & 11 & 13 & 85.00 \\
\hline Mentha longiflorum & Constipation & Laxative & 15 & 15 & 100.00 \\
\hline Anthemis tinctoria & Gastro-intestinal complaints & vomiting & 5 & 7 & 71.00 \\
\hline Artium lappa & Gastro-intestinal complaints & Anthelmintic & 1 & 1 & 100.00 \\
\hline Glycyrrhiza echinata & Gastro-intestinal complaints & Stomachic & 35 & 35 & 100.00 \\
\hline Urtica dioica & Respiratory problem & Asthma & 6 & 7 & 86.00 \\
\hline Artium lappa & Respiratory problem & Expectorant & 1 & 1 & 100.00 \\
\hline Plantago major & Dermatology problem & acne & 9 & 11 & 82.00 \\
\hline Drimia maritimia $L$. & Dermatology problem & acne & 5 & 5 & 100.00 \\
\hline Rumex acetosella & Dermatology problem & acne & 6 & 7 & 86.00 \\
\hline Phragmites australis & Dermatology problem & Skin burns & 8 & 10 & 80.00 \\
\hline Platanus orientalis & Tonic & tonic & 1 & 1 & 100.00 \\
\hline Crataegus aronia & Cardiovascular diseases & Blood pressure & 5 & 6 & 83.00 \\
\hline Rubus fruticosus & Cardiovascular diseases & Blood pressure & 5 & 7 & 71.00 \\
\hline Medicago sativa & Hematological diseases & hemorrhage & 7 & 7 & 100.00 \\
\hline Portulaca oleraceae L. & Diabetes & Diabetes & 5 & 6 & 83.00 \\
\hline Rheum ribes & Diabetes & Diabetes & 6 & 6 & 100.00 \\
\hline
\end{tabular}

a $\mathrm{Ip}=$ The number of informants who independently indicated the use of a species for the same major ailment. ${ }^{\mathrm{b}} \mathrm{Iu}=$ Total number of informants who mentioned the plant for any major ailment.

species are entering into the local medicine of people via non-traditional sources such as internet and books. Therefore, these new ways are now being exploited to introduce several traditional remedies to the new social and environmental conditions that previously were orally transmitted.

Thus, medicinal plants are often the only easily accessible health care alternative for most of the population in rural areas of Mahabad. Based on the presented results, it can be said that the use of other kinds of treatment not only do not belong to their tradition, but also are of difficult application or too expensive. However, nowadays, the use of the conventional remedies gradually changes the local medicine systems of Mahabad.

Through the investigation on the Kurdish Academy of Language (KAL) web page (http://www.kurdishacademy. org), the plant names used in Mahabad were found to be Kurdish. Based on KAL's web page, it appears that several plant names were barrowed from Persian (talkhetalkhe, revas and mazoo) and Turkish (shilan, golighamish and yonje). The most of the plant names were found to be derived from Kurdish. The plants used in Mahabad are known by the same or different local names in various parts of west Azerbayjan province (Figure 1). Nagadeh and Miyandoab are close to our field of study and placed in west Azerbayjan province. However, names of some local plants used in these areas are different since the local people in these regions are from Turkisk tribes. In addition, it was seen that the local names of some plants used in Mahabad were not the same between other kurdish tribes in West Azerbaijan and parts of Kurdistan. For example, the local names of the plants for Thymus kotschyanus (jatra; hezbi), Glycyrrhiza echinata (memook; giyah belk), Echinops ritrodes Bunge (kartashi; toosi), Medicago sativa (yonje; vinjh), Malvasyl vestris (haji laklak; tuleke), Anthemis tinctoria (bayboon; gole hajianeh) and Rubus fruticosus (drdook; toork) in which the former and latter names in practices stand for local names in Kurdish tribes of Mahabad and Kurdish tribes of other regions, respectively.

Finally, it appears that the participation of indigenous people in conservation of Mahabad bio-diversity is important. Strengthening protected area and indigenous land management could lead to the conservation of Mahabad forest and its biodiversity. On the other hand, conservation programs can also promote the livelihoods 
of indigenous people by consolidating their land rights. Therefore, conservation programs could help in increasing family incomes and, accordingly, greater control of Mahabad forests by indigenous peoples.

\section{CONCLUSION}

In the recent years, medicinal plants and the related data are being extremely exhausted in Mahabad due to deforestation, environmental degradation and migrations of traditional medicinal healers to other jobs. Several negative features of the local medicine of Mahabad lie in its dependence on low levels of information. The results of our ethnobotanical survey show that, for example, THPs are not aware of the toxicity of the medicinal plants in the area. However, it should be highlighted that despite this drawback, it is rational to affirm that large portions of the Mahabad population use local medicines due to lack of proper medical treatment as well as being far away from urban areas to rural areas. Moreover, this study shows that traditional knowledge is constantly changing and adapting, using non-traditional sources. It seems that the most cited species in terms of RI, FL, Fic and UV are significance enough to be analyzed in laboratories in order to assay their pharmaceutical aspects. Therefore, high quantitative indexes in this area may potentially lead to future investigations of global interest. Furthermore, it appears that if ethnobotanical survey is supported by phytochemical investigation could open the way toward the discovery of bioactive compounds. In this direct, priority should be given to phytochemical investigation of plants that scored the highest FL, FIC, RI values; as such values could be considered as a good indicator of potential plants for discovering new drugs. Finally, it appears the incorporating local medicinal plants in the health care delivery system will be a fruitful stage in the country.

\section{ACKNOWLEDGMENTS}

The authors express a lot of thanks to all the Traditional Health Practitioners and people involved in the interviews for providing information about the medicinal applications of the plants. In addition, we appreciate for financial supports of Tabriz University of Medical Sciences.

\section{REFERENCES}

Afshar I. The Iranian's traditional medicine. Tehran: Homa Press; 1992.
Amin G. Popular medicinal plants of Iran. Tehran: Iranian Research Institute of Medicinal Plants; 1991.

Al-Qura'n S. Ethnobotanical survey of wild medicinal plants in Showbak, Jordan. J Ethnopharmacol. 2009;123(1):45-50.

Ayyanar M, Ignacimuthu S. Ethnobotanical survey of medicinal plants commonly used by Kani tribals in Tirunelveli hills of Western Ghats, India. J Ethnopharmacol. 2011;134(3):851-64.

Bakhtiyari S. The comprehensive atlas of Iran. Tehran: Geographic and Cartographic Publication; 2015.

Balick MJ, Cox PA. Plants, people, and culture: the science of ethnobotany. New York: Scientific American Library. 1996.

Baydoun S, Chalak L, Dalleh H, Arnold N. Ethnobotanical survey of medicinal plants used in traditional medicine by the communities of Mount Hermon, Lebanon. J Ethnopharmacol. 2015;173(1):139-56.

Bennett BC, Prance GT. Introduced plants in the indigenous pharmacopoeia of Northern South America. Econ Bot. 2000;54(1):90-102.

Bitu VDCN, Matias EFF, Lima WP, Portelo AC, Coutinho HDM, Menezes, IRA. et al. Ethnobotanical study of plants sold for therapeutic purposes in public markets in Northeast Brazil. J Ethnopharmacol. 2015;172(1):265-72.

Chintamunnee V, Fawzi Mahomoodally M. Herbal medicine commonly used against non-communicable diseases in the tropical island of Mauritius. J Herbal Med. 2012;2(4):113-25.

Cotton CM. Ethnobotany: principle and application. New York: John Wiley; 1996.

Cox PA, Balick MJ. The ethnobotanical approach to drug discovery. Sci Am. 1994;270(6):82-7.

Duke JA. Handbook of medicinal herbs. Boca Raton: CRC Press; 1988. p.483-484.

Friedman J, Yaniv Z, Dafni A, Palewitch D. A preliminary classification of the healing potential of medicinal plants, based on a rational analysis of an ethnobotanical field survey among Bedouins in the Negev desert, Israel. J Ethnopharmacol. 1986;16(2/3):275-87. 
Giday M, Asfaw Z, Woldu Z. Ethnomedicinal study of plants used by Sheko ethnic group of Ethiopia. J Ethnopharmacol. 2010;132(1):75-85.

Ghorbani A. Studies on pharmaceutical ethnobotany in the region of Turkmen Sahra, north of Iran (Part 1): general results. J Ethnopharmacol. 2005;102(1):58-68.

Heinrich M, Gibbons S. Ethnopharmacology in drug discovery: an analysis of its role and potential contribution. J Pharm Pharmacol. 2001;53(4):425-32.

Jafarirad S, Damanafshan MJ. Quantitative investigation on ethnobio-pharmacological parameters of indigenous medicinal plants of Darab region, Fars, Iran. Pharmacologyonline. 2017;2:101-9.

Kadir MF, Bin Sayeed MS, Shams T, Mia MMK. Ethnobotanical survey of medicinal plants used by indigenous and tribal people in Rangamati, Bangladesh. J Ethnopharmacol. 2012;144(3):62737.

Kpodar MS, Lawson-Evi P, Bakoma B, Eklu-Gadegbeku K, Agbonon A, Aklikokou K, et al. Ethnobotanical survey of plants used in the treatment of diabetes mellitus in south of Togo (Maritime Region). J Herbal Med. 2015;14(1):196-212.

Longo R. Le monografie Tedesche, Italian Version. Milan: Studio Edizioni; 1994. v.2, p.226.

Laizer SJ. Martyrs, traitors, and patriots: Kurdistan after the Gulf War. London: Zed Books; 1996. p.56.

McDowall D. A modern history of the Kurds. London: Tauris; 1996.

Miraldi E, Ferri S, Mostaghimi V. Botanical drugs and preparations in the traditional medicine of West Azerbaijan (Iran). J Ethnopharmacol. 2001;75(2/3):77-87.

Mir Heidari H. Encyclopedia of medicinal plants of Iran. Tehran: Islamic Culture Press; 1993.

Mosaddegh M, Naghibi F, Moazzeni H, Pirani A, Esmaeili S. Ethnobotanical survey of herbal remedies traditionally used in Kohghiluyehva Boyer Ahmad province of Iran. J Ethnopharmacol. 2012;141(1):80-95.
Neves JM, Matos C, Moutinho C, Queiroz G, Gomes LR. Ethnobotanical notes about ancient uses of medicinal plants in Trás-os-Montes (northern of Portugal). J Ethnopharmacol. 2009;124(2):270-83.

Poffenberger M, McGean B, Khare S, Campbell J. Field method manual, community forest economy abd use pattern: Participatoey and Rural Appraisal (PRA) methods in South Gujarat India. New Delhi: Society for Promotion of Wastelands Development; 1992. v.2.

Ragupathy S, Steven NG, Maruthakkutti M, Velusamy B, UlHuda M M. Consensus of the 'Malasars' traditional aboriginal knowledge of medicinal plants in the Velliangiri holy hills, India. J Ethnobiol Ethnomed. 2008;4(1):1-14.

Rai LK, Prasad P, Sharma E. Conservation threats to some important medicinal plants of the Sikkim Himalaya. Biol. Cons. 2000; 93(1):27-33.

Rehecho S, Uriarte-Pueyo I, Calvo J, Vivas LA, Calvo MI. Ethnobotanical survey of medicinal plants in Nor-Yauyos, a part of the Landscape Reserve Nor-Yauyos-Cochas, Peru. J Ethnopharmacol. 2011;133(1):75-85.

Rojhan MS. Herbal drugs and treatment with medicinal plants. Isfahan: Marshal Press; 1991.

Rokaya MB, Münzbergová Z, Timsina B. Ethnobotanical study of medicinal plants from the Humla district of western Nepal. J Ethnopharmacol. 2010;130(3):485-504.

Samoisy AK, Mahomoodally MF. Ethnobotanical analysis of medicinal plants used against non-communicable diseases in Rodrigues Island, Indian Ocean. J Ethnopharmacol. 2015;173(1):20-38.

Stevens PF. (2001 onwards). Angiosperm Phylogeny Website. Version 14, July 2017 http://www.mobot.org/MOBOT/research/ APweb/

Tchouya GRF, Souza A, Tchouankeu JC, Yala JF, Boukandou M, Foundikou H, Obiang GD, Boyom FF, Mabika RM, Menkem EZ, Ndinteh DT, Lebibi J. et al. Ethnobotanical surveys and pharmacological studies of plants used in traditional medicine in the treatment of HIV/AIDS opportunistic diseases in Gabon. J Ethnopharmacol. 2015;162(3):306-16. 
Telefo PB, Lienou LL, Yemele MD, Lemfack MC, Mouokeu C, Goka CS, Tagne SR, Moundipa FP, et al. Ethnobotanical survey of plants used for the treatment of female infertility in Baham, Cameroon. J Ethnopharmacol. 2011;136(1):178-87.

Yavuz M, Selami P, Selvi S, Savran A. Ethnobotanical survey of medicinal plants in Ulukışla (Niğde-Turkey). J Herbal Med. 2016;6(1):42-48.
Zargari A. Medicinal plants. Tehran: University Publication; 1992.

Received for publication on $01^{\text {st }}$ March 2018 Accepted for publication on $21^{\text {st }}$ May 2018 